\title{
Rules Regulating the Change in Physiological Parameters of Rats Under Simulated Microgravity and Different Ambient Temperatures
}

\author{
Jie Qian ${ }^{1,2, ~ *, ~ G e n g x i n ~ X i e ~}{ }^{1,2}$, Jie Zheng ${ }^{1}$, Bo Duan ${ }^{1}$, Yajun Cao ${ }^{1}$ Xi Wang ${ }^{1,2}$, Fengjie $\mathrm{Li}^{3}$, \\ Changpeng $\mathrm{Hu}^{3}$ \\ ${ }^{1}$ School of Urban Construction and Environmental Engineering, Chongqing University, Chongqing, China \\ ${ }^{2}$ Center of Space Exploration, Ministry of Education, Chongqing, China \\ ${ }^{3}$ Department of Pharmacy, The Second Affiliated Hospital, Army Medical University, Chongqing, China
}

Email address:

qianjie_cqu@126.com (Jie Qian),xiegengxin@vip.sina.com (Gengxin Xie),jzheng5@qq.com (Jie Zheng)

${ }^{*}$ Corresponding author

\section{To cite this article:}

Jie Qian, Gengxin Xie, Jie Zheng, Bo Duan, Yajun Cao, Xi Wang, Fengjie Li, Changpeng Hu. Rules Regulating the Change in Physiological Parameters of Rats Under Simulated Microgravity and Different Ambient Temperatures. American Journal of Civil Engineering.

Vol. 7, No. 1, 2019, pp. 27-34. doi: 10.11648/j.ajce.20190701.15

Received: January 18, 2019; Accepted: March 25, 2019; Published: April 28, 2019

\begin{abstract}
To investigate the rules regulating changes in mean chest temperature (MCT), mean rectal temperature (MRT) and mean body weight (MW)in rats at simulated microgravity and different ambient temperatures (ATs). The $-30^{\circ}$ rat tail suspension (TS) method was used to simulate microgravity over a 7 day period at $18^{\circ} \mathrm{C}, 20^{\circ} \mathrm{C}, 23^{\circ} \mathrm{C}$ and $26^{\circ} \mathrm{C}$ AT through comparison between the TS group and control group. Each group contained six male SD rats (including one verification rat). MCT and MRT of TS group rats increased at all four levels of AT. MCT and MRT reached maximum growth rates of 0.315 and 0.118 at ATs of $20^{\circ} \mathrm{C}$ and $23^{\circ} \mathrm{C}$, respectively. MW was reduced at ATs of $20^{\circ} \mathrm{C}$ and $23^{\circ} \mathrm{C}$, whereas it increased at $18^{\circ} \mathrm{C}$ and $26^{\circ} \mathrm{C}$ AT in the TS group. The rates of changes of MCT, MRT and MW at different ATs were analyzed using linear regression analysis for both the control (Equation 1) and TS (Equation 2) groups. Using A new equation (Equation 3) without the influence of other factors was derived after Equation 1 minus Equation 2 to derive. The result shows that the coefficients of Equation 3 are different under the four ATs. TS and AT have coupling effects on the MCT, MRT and MW of rats.
\end{abstract}

Keywords: Tail Suspended Rats, Mean Chest Temperature, Mean Rectal Temperature, Mean Body Weight, Ambient Temperature

\section{Introduction}

Relatively few studies on human thermal comfort under microgravity values exist. However, it has been shown that weightlessness can change the physiology of the human body [1-6]. The distribution of body fluid in the head [7-9]causes body temperature to decrease in the lower body and increase in upper body, resulting in muscle atrophy because of a decrease in heat dissipation [10-12], the deterioration of cardiovascular function [13-20] and the weakening of metabolism. Recent research [26] has also found that the core temperature of the human body can rise by $1{ }^{\circ} \mathrm{C}$ after long periods in space. These effects are likely to result in changes in thermal comfort requirements of the human body.

The research on thermal comfort of human body on the earth is generally based on the principle of statistics and realized by large sample human experiments [28-31]. However, in microgravity environment, due to technical, equipment and economic reasons, it is impossible to use large samples of human experiments right now. At the same time, in order to avoid the harm of the experiment to human body, after many comparisons and experts' demonstrations, it is decided to use the animal experiment of simulated microgravity on the ground to study the relationship between ambient temperature and related physiological indexes of animal thermal comfort.

In the present paper, the rat TS method was used to simulate the microgravity environment. By comparison with the 
control group, the changes of physiological parameters related to thermal comfort in rats under four levels of AT were studied and analyzed. The study results will provide clues for the study of the relationship between environmental temperature and physiological indexes related to human thermal comfort under microgravity and the study of reflecting human thermal comfort through physiological indexes under microgravity.

\section{Subjects and Methods}

\subsection{Subjects}

Healthy male SPF class SD rats were chosen which supplied by the Animal Experimental Center of The Second Affiliated Hospital within the Army Medical University. Each rat weighed $250 \mathrm{~g} \pm 50 \mathrm{~g}$.

\subsection{Feeding Environment}

The TS rats were fed individually by placing each rat in a cage designed by the research group. The experimental environment was maintained at $60 \% \pm 10 \%$ relative humidity, normal indoor atmospheric pressure and air temperature set according to the experiment requirements. A $12 \mathrm{~h}: 12 \mathrm{~h}$ light: dark cycle was maintained using fluorescent lamps.

\subsection{Methods}

\subsubsection{Weightlessness Model}

The TS method [21], [22] was used, with the heads of rats maintained at approximately $30^{\circ}$ below the horizontal and the hind legs dangling. Each control rat was kept and fed in a single cage in which it could move freely. All rats were allowed free access to food and water.

After 3 days of concentrated adaptive feeding, excluding the lightest, heaviest rats and abnormal rats, all rats were divided into a TS group and a control group, in which each group contained five rats.

Table 1. Experimental grouping.

\begin{tabular}{|c|c|c|c|c|c|c|c|c|}
\hline \multirow{2}{*}{$\begin{array}{l}\text { Ambient } \\
\text { Temperature }\end{array}$} & \multicolumn{2}{|l|}{$18^{\circ} \mathrm{C}$} & \multicolumn{2}{|l|}{$20^{\circ} \mathrm{C}$} & \multicolumn{2}{|l|}{$23^{\circ} \mathrm{C}$} & \multicolumn{2}{|l|}{$26^{\circ} \mathrm{C}$} \\
\hline & TS Group & Control Group & TS Group & Control Group & TS Group & Control Group & TS Group & Control Group \\
\hline Rats Number & 5 & 5 & 5 & 5 & 5 & 5 & 5 & 5 \\
\hline
\end{tabular}

Note: relative humidity $60 \% \pm 10 \%$, wind speed $0.02 \pm 0.01 \mathrm{~m} / \mathrm{s}$, indoor standard atmospheric pressure, daily fluorescent lamp, lighting $12 \mathrm{~h}$.

\subsubsection{Experimental Arrangement}

The experimental ambient temperature was varied between $18^{\circ} \mathrm{C}, 20^{\circ} \mathrm{C}, 23^{\circ} \mathrm{C}$ and $26^{\circ} \mathrm{C}$ (Table 1$)$.

\subsubsection{Test Method}

Measurements of rat weight, chest temperature and rectal temperature were taken by the same experiment team at 8:00 11:00am daily to reduce the influence of the circadian rhythm. The experimental data were processed using the SPSS18.0 software and bad data were eliminated.

All above experimental methods were confirmed and approved by the hospital Ethics Committee.

\subsubsection{Instruments}

All instruments used are listed below.
Environmental parameter test: KANOMAX (A533); Weight test: CAMRY (EK4150);

Chest temperature test: Shanghai Huachen mercury thermometer (WBG-0-2);

Rectal temperature test: Microlife (MT16C2).

\section{Results and Discussion}

\subsection{Mean Chest Temperature (MCT)}

Experimental results of chest temperature were averaged and the data were used to draw fitting curves (Figure 1). Figure 1 shows the data of the validation group at four ambient temperatures (ATs).

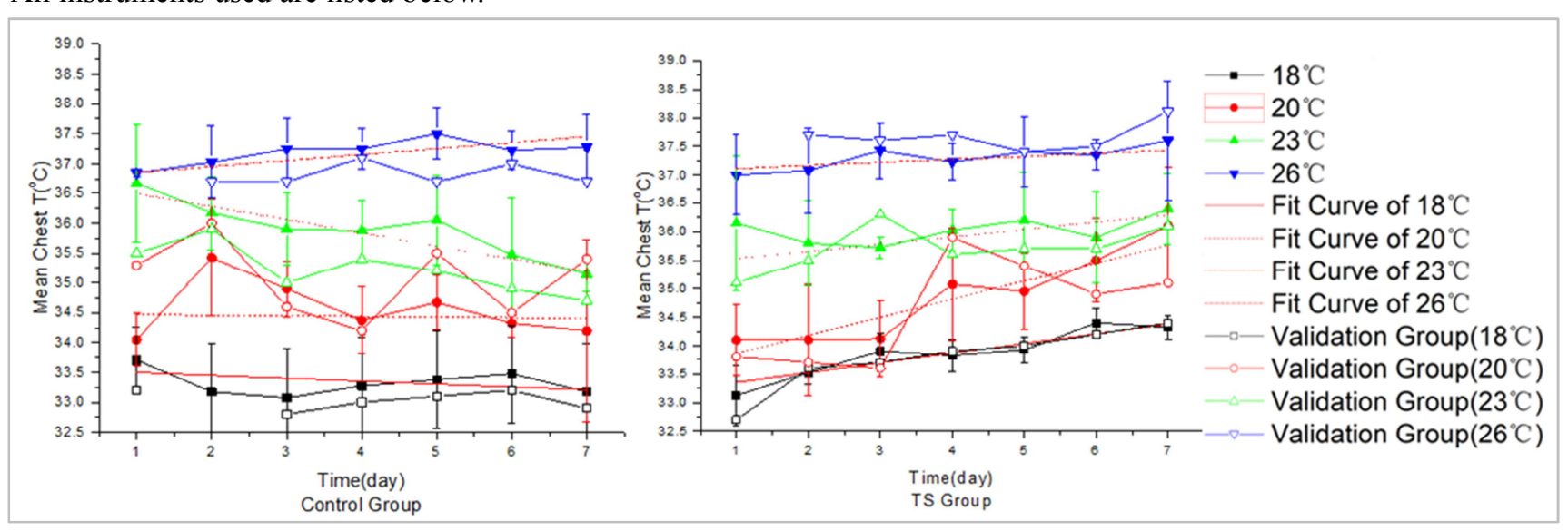

Figure 1. Mean chest temperature (MCT) curve of rats. 
shows the MCT for the control group under four different ATs over the first 7 days. The following characteristics are evident: 1. At an $\mathrm{AT}$ of $26^{\circ} \mathrm{C}, \mathrm{MCT}$ shows a slight increasing trend over time which can be considered constant; 2 . The MCTs of the other three rats show general downward trends with some fluctuations; 3. On any particular day, the MCT at a higher AT is higher than the MCT at a lower AT.

The right-hand side graph of Figure 1 shows the MCT curves of the TS group under four different ATs over the first 7 days. The following characteristics are evident: 1. All four curves show a rising trend; however, the rates of increase differ among the different ATs; 2. Under any AT, the MCT is higher than that of the control group on the 7thday; 3 . On any particular day, the MCT at a higher AT is higher than the MCT at a lower AT. The rising trend of MCT within the TS group is possibly because the distribution of body fluid in the head [23-25], which would be a conclusion that is consistent with previous literature results.

The low values of chest temperature were due to somedata being rejected due to an experimental error.

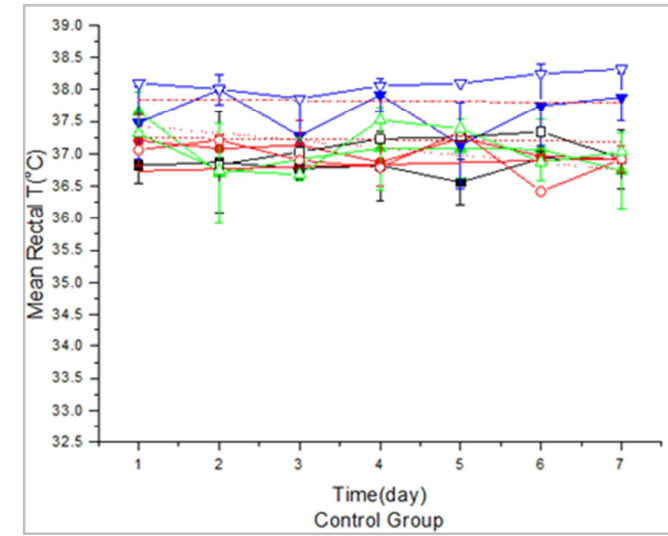

\subsection{Mean Rectal Temperature (MRT)}

Experimental results of rectal temperature were averaged and used to draw fitting curves (Figure 2). The lines shown in Figure 2 represent linear fitting curves of MRT under four different values of AT.

The left-hand side graph shown in Figure 2 shows the MRT for the control group under four different ATs over the first 7 days. The following characteristics are evident: 1 . Although the MRT curve at $26^{\circ} \mathrm{C}$ AT shows fluctuations, constant trends of slight decrease are evident at $23^{\circ} \mathrm{C}$ and $20^{\circ} \mathrm{C} ; 2$. The MRT curve of rats at $18^{\circ} \mathrm{C}$ AT shows a slight increasing trend; 3 . The amplitude of the MRT curve is less than $0.7^{\circ} \mathrm{C}$, which is smaller than that of rats in the control group.

The right-hand side graph of Figure 2 shows the MRT curves of the TS group under four different ATs over the first 7 days. The following characteristics are evident: 1. All four show rising trends, with the rate of change larger for an AT of $26^{\circ} \mathrm{C} \mathrm{AT} ; 2$. The MRT values are higher than those of the control group on the 7 th day under the four ATs.

Figure 2. Mean rectal temperature (MRT) curves of rats.

\subsection{Mean Body Weight (MW)}

The MW curves are shown in Figure 3. The lines in Figure 3 represent linear fitting curves of the MW of rats under different AT.

The left-hand side of Figure 3 represents the control group and has the following characteristics: 1 . All four curves show a rising trend; 2 . The rates of increase of all curves are nearly the same, with the biggest rate evident at $20^{\circ} \mathrm{C} \mathrm{AT}$.

The right-hand side of Figure 3 represents the TS group, and has the following characteristics: 1 . The MW curves under ATs of $20^{\circ} \mathrm{C}$ and $23^{\circ} \mathrm{C}$ show rising trends, whereas the others show decreasing trends; 3 . On the second day, all MW values under all ATs were less than those over the first day.
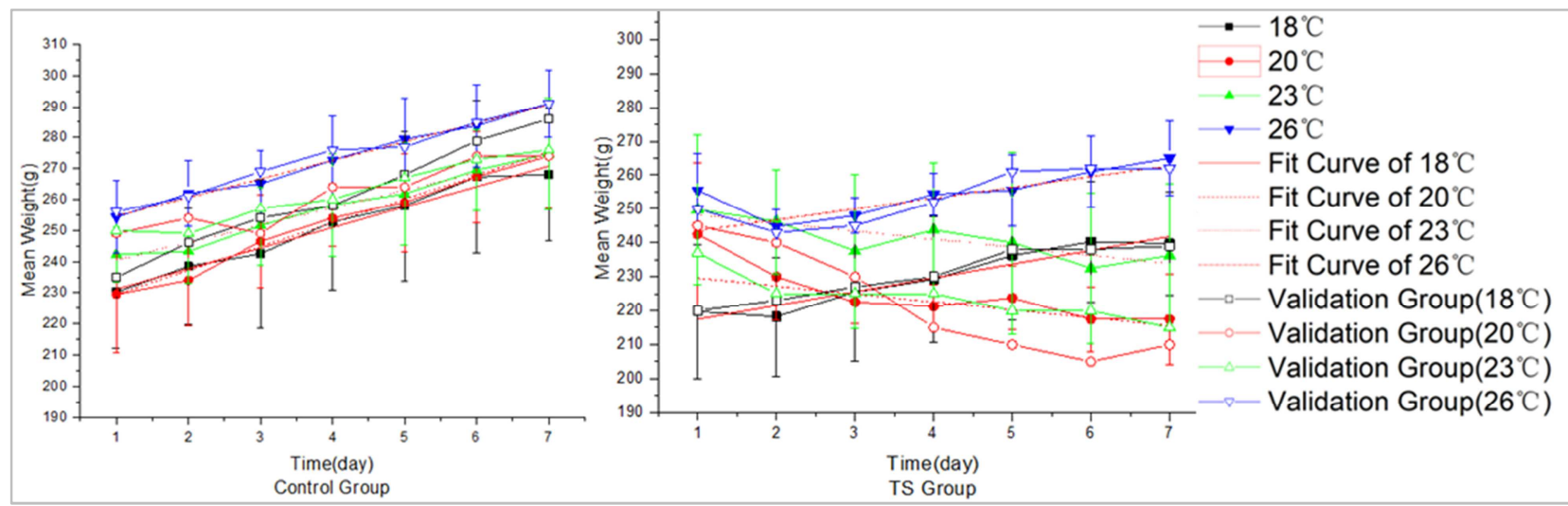

Figure 3. The mean weight $(M W)$ curve of rats. 


\subsection{Discussion}

The two characteristics of MCT in the control group, as evident in the left-hand side graph of Figure 1, infers that the thermal balance of MCT of rats at around $26^{\circ} \mathrm{C}$ AT is around $37^{\circ} \mathrm{C}$, with lower MCT at lower ATs of $23^{\circ} \mathrm{C}, 20^{\circ} \mathrm{C}$ and $18^{\circ} \mathrm{C}$ according to the downward trend of MCT curves. These results infer that as the AT decreases, the body temperatures (MCTs) of control group rats are reduced, mainly through physiological regulation to maintain homeostasis and reduce body surface heat dissipation. Although rats were tail suspended to obtain data for the MCT curves shown in Figure 1 (right-hand graph), it can be inferred that the tail suspension broke down the thermal balance as compared with the control group. The increase in chest heat was greater than heat loss; therefore, the chest temperatures of rats increased, and was also higher than that in the control group on the 7th day.

MRT appears to be less affected by AT when comparing MCT of the control group and TS group. However, compared with the control group, the MRT values of TS group rats show a slight upward trend, except at $20^{\circ} \mathrm{C}$ AT. In addition, the MRT values of the TS group on the 7th day were consistently higher than those of the control group. These results appear to show that tail suspension will promote a weak increase of rectal temperature in rats.

Tail suspension affected the weight gain of TS group rats. The results of our experiment are in line with those obtained in previous studies [27].

\section{Analysis}

\subsection{Factor Analysis}

Previous studies did not perform a correlation analysis between physiological parameters of rats under tail suspension with AT. Therefore, the hypothesis that the influences of AT and tail suspension on the three physiological parameters (MCT, MRT, MW) in rats are independent was constructed.

As the hypothesis, the equation of tail suspension and the three physiological parameters in rats can be obtained from the TS group linear regression equation minus control group linear regression equation. The principle of the aforementioned is as shown in the equation below:

$$
\mathrm{F}_{\mathrm{ts}}(\mathrm{t})=\mathrm{Fc}(\mathrm{t})+\mathrm{kt}+\mathrm{T}_{0}\left(\mathrm{w}_{0}\right) \rightarrow \mathrm{F}_{\mathrm{ts}}(\mathrm{t})-\mathrm{Fc}(\mathrm{t})=\mathrm{kt}+\mathrm{T}_{0}\left(\mathrm{w}_{0}\right)
$$

$\mathrm{F}_{\mathrm{ts}}(\mathrm{t}): \mathrm{MCT} / \mathrm{MRT} / \mathrm{MW}$ equation for tail-suspended rats;

$\mathrm{Fc}(\mathrm{t})$ : theMCT/MRT/MW equations of the control rat;

$\mathrm{K}$ : the slope of MCT/MRT/MW and AT;

$\mathrm{T}_{0}\left(\mathrm{w}_{0}\right)$ : initialMCT/MRT/MW.

It is evident that the three slopes calculated in Table2 differ. This is at odds with the hypothesis that AT and tail suspension were independent to the three physiological parameters measured. Therefore, it may be concluded that AT and tail suspension are coupled to the three parameters in rats.

Table 2. Table of slope.

\begin{tabular}{lllll}
\hline $\mathbf{A T}\left({ }^{\circ} \mathbf{C}\right)$ & $\mathbf{1 8}$ & $\mathbf{2 0}$ & $\mathbf{2 3}$ & $\mathbf{2 6}$ \\
\hline $\mathrm{k}_{\text {MCT }}$ & 0.310 & 0.229 & 0.196 & 0.211 \\
$\mathrm{k}_{\text {MRT }}$ & 0.068 & -0.002 & 0.112 & 0.12 \\
$\mathrm{k}_{\text {MW }}$ & -3.536 & -7.929 & -6.321 & -1.357 \\
\hline
\end{tabular}

Note: All slopes shown are the averages of fiverats, including the validation rat.

\subsection{Analysis of the Laws Regulating the Change in Slope}

Taking AT as the independent variable and the slopes shown in Table2 as the dependent variable, nonlinear curve regressions were constructed using Origin Pro 8.0 software, and the corresponding curve equations and graphs were obtained (Figure 4).

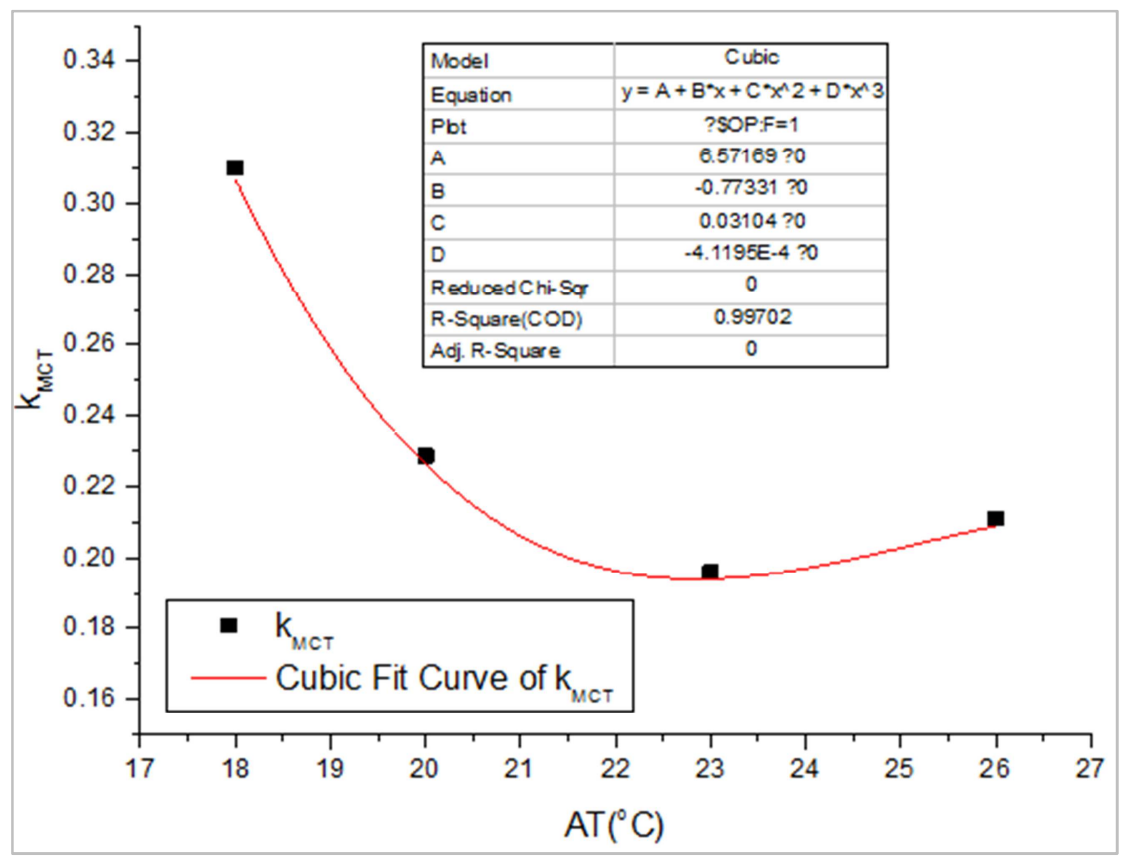



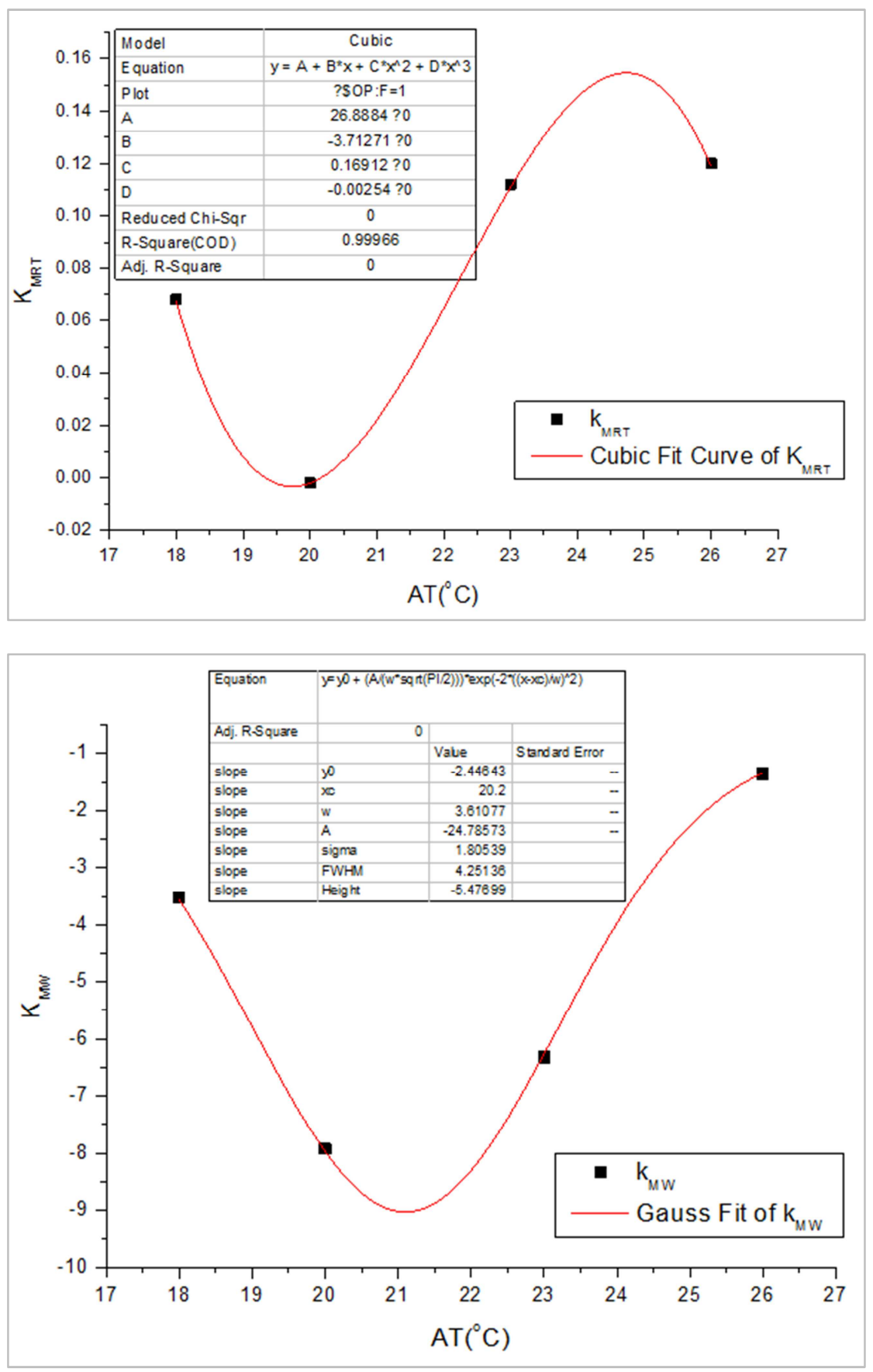

Figure 4. Nonlinear curve regression of $k_{M W}, k_{M C T}$ and $k_{M R T}$.

The relationship between the $\mathrm{k}_{\mathrm{MCT}}$ and the $\mathrm{AT}$ in rats was:

$$
\mathrm{k}_{\text {мст }}=6.57169-0.77331 \mathrm{t}+0.03104 \mathrm{t}^{2}-0.00041 \mathrm{t}^{3} \quad \mathrm{R}^{2}=0.997
$$

Where t represents AT $\left({ }^{\circ} \mathrm{C}\right.$; range $\left.18-26^{\circ} \mathrm{C}\right)$.

The equation above can be considered to describe the influence of AT on $\mathrm{k}_{\mathrm{MCT}}$ under pure tail suspension. Obtaining the equation of MCT and AT on Earth (control group) allows us to obtain the equation of MCT and AT under a weightlessness environment (tail suspension).

The top left-hand side of Figure 4 shows the following characteristics: 1 . all $\mathrm{K}_{\mathrm{MCT}}$ values are greater than 0 , that is to say, at all the experimental ATs, the tail suspension factor promoted the increase of chest temperature, consistent with previous research results ${ }^{5,6,23}$, probably because the distribution of body fluid in the head differs after tail suspension. 2. The distribution of $\mathrm{K}_{\mathrm{MCT}}$ is not linear with $\mathrm{AT}$, and the minimum value is 0.196 when the $\mathrm{AT}$ reaches $23^{\circ} \mathrm{C}$. With the AT rising or decreasing, the $\mathrm{K}_{\mathrm{MCT}}$ will increase; 3 . $\mathrm{K}_{\mathrm{MCT}}$ are different under different AT; however, the increased rates of the TS group at different AT is close to that of the MCT. This contradiction verified that the two factors of AT and tail suspension were due 
to the coupling effects of chest temperature in rats. However, why $\mathrm{K}_{\mathrm{MCT}}$ has such characteristics requires further research on the underlying mechanism.

Rectal temperature is one of the main indices used to measure the health status of rats. A temperature that is too high or too low is indicative of poor health of the rats. Consistent with this principle, the regression curve equation for rectal temperature under tail suspension was calculated:

$$
\mathrm{k}_{\mathrm{MRT}}=26.8884-3.71271 \mathrm{t}+0.16912 \mathrm{t}^{2}-0.00254 \mathrm{t}^{3} \quad \mathrm{R}^{2}=0.999
$$

As according to the regression formula and tope right-hand side graph of Figure 4, nearly all $\mathrm{k}_{\mathrm{MRT}}$ values are above 0 in the range of experimental $\mathrm{AT}$. When the $\mathrm{AT}$ is $20^{\circ} \mathrm{C}$, the minimum value of $\mathrm{K}_{\mathrm{MRT}}$ is -0.002 , and the highest value of $\mathrm{K}_{\mathrm{MRT}}$ of around 0.15 occurs at an AT of approximately $24.5^{\circ} \mathrm{C}$.

From this fitting formula, $\mathrm{K}_{\mathrm{MRT}}$ changes within a certain range; however, the changes evident in the MRT of the control and TS groups, as evident in Figure 2, change over a smaller range. This may not be due to the effect of tail suspension on rat MRT, but rather due to the strong ability of the rats to resist tail suspension and the AT interference. It is more likely that these observations are due to the ability for physiological adjustment by the rats to control the fluctuation of MRT in a very small range.

Similar to Equation 3 above, the regression equation of rat $\mathrm{k}_{\mathrm{MW}}$ and AT under tail suspension was obtained:

$$
\mathrm{K}_{\text {мш }}=-0.7+\left(-44.5 /(4.25 * \sqrt{\pi / 2})^{0.5}\right) \mathrm{e}^{\left(-2((t-21.2) / 4.25)^{2}\right)} \quad \mathrm{R}^{2}=0.999
$$

The regression curve has the following characteristics: 1 . Under the influence of tail suspension, the values of the entire regression curve were less than 0; i.e., the weights of all rats decreased during tail suspension. However, as evident in the right-hand side graph of Figure 3, the weights of rats in the TS group were raised at ATs of $18^{\circ} \mathrm{C}$ and $26^{\circ} \mathrm{C}$, indicating that the AT and tail suspension had a coupling effect on the degree of MW change. In addition, under different AT, the influence of the two factors on MW differed; 2. The minimum and maximum values of the regression curve appeared at the AT of $21^{\circ} \mathrm{C}$, and the $\mathrm{k}_{\mathrm{MW}}$ reached a minimum of almost -9 . Consequently, with the increase or decrease of AT, $k_{\mathrm{MW}}$ increased, and the weight loss of rats decreased.

However, due to the lack of data, the fitting regression of KMRT and KMW is only based on the knowledge of the author. To obtain a clear trend, more samples and data are required. The fitting regression of KMCT also requires further verification.

\subsection{Verification}

One rat was used to verify each group. On the whole, a consistent trend was evident, although there was also a high deviation. The highest deviation at $23^{\circ} \mathrm{C}$ AT was for chest temperature of the TS group, which was $-1.0^{\circ} \mathrm{C}$. Figure 1 shows that the chest temperature of the control group deviated from $1.2^{\circ} \mathrm{C}$ at $20^{\circ} \mathrm{C} \mathrm{AT}$, whereas the chest temperature of the TS group validation fluctuated to $-0.7^{\circ} \mathrm{C}$.

Figure 2 shows that under an AT of $26^{\circ} \mathrm{C}$, the rectal temperature of the control group deviated from the maximum temperature of $-1.2{ }^{\circ} \mathrm{C}$, whereas the positive and negative deviations of the TS group were generally within $0.6^{\circ} \mathrm{C}$.

The trend of weight change was generally consistent, and the trends of validation showed that the control and TS groups basically fitted with experimental data.

\section{Conclusion and Prospect}

\subsection{Conclusion}

The rat tail suspension method was used to simulate microgravity, with the results compared against the control group. The MCT, MRT and $\mathrm{MW}$ at $18^{\circ} \mathrm{C}, 20^{\circ} \mathrm{C}, 23^{\circ} \mathrm{C}$ and $26^{\circ} \mathrm{C}$ were studied. The following conclusions can be drawn:

(1) The influence of AT and tail suspension on the MCT, MRT and MW of rats is a coupling relationship.

(2) The change in rectal temperature in rats is relatively small, both in the control and TS groups. This is probably due to the ability of rats to physiologically adjust to control the fluctuation of MRT over a very small range.

\subsection{Prospect}

In the current study, two regression equations were used to eliminate the interference term, and the influence of TS on MCT, MRT and MW of the rats at different ATs was obtained. It is deduced that TS and AT are coupled to the three physiological parameters of rats. This method can be used in research and application of human thermal comfort under simulated microgravity. After eliminating the interference term equation, the data obtained under Earth gravity can superpose the equation to obtain the values of related physiological parameters under simulated microgravity.

To reduce the influence of the $24 \mathrm{~h}$ circadian rhythm, the data collected time was concentrated over the period 8:00 am11:00 am every morning in the experiment. However, a more accurate and meaningful interpretation can be obtained by monitoring the physiological parameters of the rats in real time. Therefore, there would be great advantage in using advanced technology to monitor rats in real time without interference.

In the present study, the physiological changes in rats were tested over the first 7 days; however, the cycle of physiological change occurring though weightlessness occurs over a cycle that is far longer than 7 days. Therefore, the period of study needs to be lengthened. At the same time, there are obvious differences between rat and human bodies. Whether the results obtained from research on rats can be applied to humans requires further verification. However, research of rats remains the most direct and accurate method 
available to study the human body.

\section{Acknowledgements}

I would like to acknowledge the assistance of my supervisors, Professor GengxinXie and Professor JieZheng. I also acknowledge the Animal Experiment Center of Xinqiao Hospital for use of facilities and experimental instruments. I am thankful to FengjieLi and Changpeng Hu for assistance in running experiments and to BoDuan and YajunCao for conducting measurements.

\section{Funding}

Basic business fee project of the Central University (106112017CDJJGGF0001).

\section{References}

[1] Drummer, C., Heer, M., Dressendorfer, R. A., Strasburger, C. J. andGerzer, R., Reduced natriuresis during weightlessness. Clin. Investig., 1993,71, 678-686.

[2] Drummer, C., Gerzer, R., Baisch, F. andHeer, M., Body fluid regulation in $\mu$-gravity differs from Earth: an overview. Pflugers Arch., 2000, 441, 66-72.

[3] Leach, C. S., Alfrey, C. P., Suki, W. N., Leonard, J. I., Rambaut, P. C., Inners, L. D., Smith, S. M., Lane, H. W. andKrauhs, J. M., Regulation of body fluid compartments during short-term spaceflight. J. Appl. Physiol., 1996, 8, 105-116.

[4] Zhuang, X. and Chen, F., Weightlessness Physiology. People's Military Medical Press, China, 1990. (in Chinese).

[5] Shen, S., Weightlessness physiology technology and progress. National Defense Industry Press, China, 2007. (in Chinese).

[6] Pavy-Le Traon, A., Heer, M., Narici, M. V., Rittweger, J. andVernikos. J., From space to Earth: advances in human physiology from 20 years of bed rest studies (1986-2006). Eur. J. Appl. Physiol., 2007,101, 143-194.

[7] Klein-Nulend, J., Bacabac, R. G., Veldhuijzen, J. P. andvan Loon, J. J., Microgravity and bone cell mechanosensitivity. Adv. Space Res., 2003, 32, 1551-1559.

[8] McGarry, J. G., Klein-Nulend, J., Mullender, M. G. and Prendergast, P. J., A comparison of strain and fluid shear stress in stimulating bone cell responses: a computational and experimental study. FASEB J., 2005, 19, 482-484.

[9] Burger, E. H., Klein-Nulend, J. and Smit, T. H., Strain-derived canalicular fluid flow regulates osteoclast activity in a remodelling osteon: a proposal. J. Biomech., 2003, 36, 1453-1459.

[10] Convertino, V. A., Bloomfield, S. A. andGreenleaf, J. E., An overview of the issues: physiological effects of bed rest and restricted physical activity. Med. Sci. Sports Exerc., 1997, 29, 187-190.

[11] Ferretti, G., Girardis, M., Moia, C. andAntonutto, G., Effects of prolonged bed rest on cardiovascular oxygen transport during submaximal exercise in humans. Eur. J. Appl. Physiol. Occup. Physiol., 1998, 78, 398-402.
[12] Greenleaf, J. E., Intensive exercise training during bed rest attenuates deconditioning. Med. Sci. Sports Exerc., 1997, 29, 191-196.

[13] Iwasaki, K. I., Zhang, R., Zuckerman, J. H., Pawelczyk, J. A. and Levine, B. D., Effect of head-down-tilt bed rest and hypovolemia on dynamic regulation of heart rate and blood pressure. Am. J. Physiol. Regul. Integr. Comp. Physiol., 2000, 279, 2189-2199.

[14] Hirayanagi, K., Iwase, S., Kamiya, A., Sasaki, T., Mano, T. andYajima, K., Functional changes in autonomic nervous system and baroreceptor reflex induced by 14 days of 6 degrees head-down bed rest. Eur. J. Appl. Physiol., 2004, 92, 160-167.

[15] Linnarsson, D., Spaak, J. andSundblad, P., Baroreflex impairment during rapid posture changes at rest and exercise after 120 days of bed rest. Eur. J. Appl. Physiol., 2006, 96, $37-45$.

[16] Xiao, X., Mukkamala, R., Sheynberg, N., Williams, G. H. and Cohen, R. J., Effects of prolonged bed rest on the total peripheral resistance baroreflex. Comput. Cardiol., 2002, 29, 53-56.

[17] Kimmerly, D. S. and Shoemaker, J. K., Hypovolemia and neurovascular control during orthostatic stress. Am. J. Physiol. Heart Circ. Physiol., 2002, 282, 645-655.

[18] Kamiya, A., Iwase, S., Kitazawa, H., Mano, T., Vinogradova, O. L. and Kharchenko, I. B., Baroreflex control of muscle sympathetic nerve activity after 120 days of 6 degrees head-down bed rest. Am. J. Physiol. Regulatory Integrative Comp. Physiol., 2000,278, 445-452.

[19] Meck, J. V., Waters, W. W., Ziegler, M. G., deBlock, H. F., Mills, P. J., Robertson, D. and Huang, P. L., Mechanisms of postspaceflight orthostatic hypotension: low alpha1adrenergic receptor responses before flight and central autonomic dysregulation postflight. Am. J. Physiol. Heart Circ. Physiol., 2004, 286, 1486-1495.

[20] Blaber, A. P., Bondar, R. L. andKassam, M. S., Heart rate variability and short duration spaceflight: relationship to post-flight orthostatic intolerance. BMC Physiol., 2004,27, 4-6.

[21] Li, W. T., Huang, Y. F., Sun, L. W., Luan, H. Q. and Zhu, B. Z., Would interstitial fluid flow be responsible for skeletal maintenance in tail-suspended rats?. Microgravity Sci. Technol., 2017, 29, 107-114.

[22] Kang, H., Sun, L., Huang, Y., Wang, Z., Zhao, P., Fan, Y. andDeng, X., Regional specific adaptation of the endothelial glycocalyx dimension in tail-suspended rats. PflugersArch., 2015, 467, 1291-1301.

[23] Atkov, O. Y. andBednenko, V. S., Hypokinesia and weightlessness: clinical and physiologic aspects. International University Press, 1992.

[24] Gharib, C., Gauquelin, G., Pequignot, J. M., Geelen, G., Bizollon, C. A. andGuell, A., Early hormonal effects of head-down tilt (-10 degrees) in humans. Aviat. Space Environ. Med., 1988,59, 624-629.

[25] Greenleaf, J. E., Physiology of fluid and electrolyte responses during inactivity: water immersion and bed rest. Med. Sci. Sports Exerc., 1984,16, 20-25. 
[26] Stahn, A. C., Werner, A., Opatz, O., Maggioni, M. A., Steinach, M., von Ahlefeld, V. W., Moore, A., Crucian, B. E., Smith, S. M., Zwart, S. R., Schlabs, T., Mendt, S., Trippel, T., Koralewski, E., Koch, J., Choukèr, A., Reitz, G., Shang, P., Rőcker, L., Kirsch, K. A. and Gunga, H. C., Increased core body temperature in astronauts during long-duration space missions. Sci. Rep., 2017, 7, 16180.

[27] Nicogossian, A. E., Leach, H. C. and Pool, S. L., Space physiology and medicine. Philadelphia, PA; Lea \&Febiger, 1994.

[28] Zheng Jie, Chen Liang, Li Baizhan, et al. Indoor thermal comfort studies based on physiological parameter measurement and questionnaire investigation [J]. Journal of Central South University of Technology . 2006, 13(4): 404-407.
[29] Zheng Jie, Zhang Yu, Yao Runming. Impact of indoor thermal comfort on physiological parameters of human body [J]. Journal of Central South University of Technology. 2009, 16(s1): 024-027.

[30] P. O. Fanger, O. Östberg, A. G. McK. Nicholl, et al. Thermal comfort conditions during day and night $[\mathrm{J}]$. European Journal of Applied Physiology and Occupational Physiology. 1974, Vol33: 255-263.

[31] P. O. Fanger, J. Højbjerre, J. O. B. Thomsen. Thermal comfort conditions in the morning and in the evening [J]. International Journal of Biometeorology. 1974, Vol18:16-22. 